\title{
La competencia municipal en materia de circulación
}

Esta era una materia en la que hasta hace pocos años apenas se habían suscitado conflictos o fricciones en cuanto a las posibles competencias actuantes; por una parte, el Ministerio de Obras Públicas intervenía en las carreteras, con la regulación del tráfico en las mismas y todo lo referente a corrección de las infracciones realizadas en dicho tráfico, y, por otra, en las calles y plazas, en una palabra, en las vías municipales, dichas cuestiones quedaban dentro de la competencia municipal. En el mismo Código de la Circulación (véanse los artículos $8 .^{\circ}$, 12, 48 y 103) se refleja esta diferencia de competencias, estableciéndose taxativamente que a los Ayuntamientos les corresponde la policía de tráfico en las vías urbanas.

Pero con la promulgación, que a su vez ha sido consecuencia del incremento de tráfico y de accidentes derivados del mismo, de la Ley. de 30 de julio de 1959, provisionalmente detallada por la Orden de 5 de octubre siguiente y definitivamente por el Decreto de 21 de julio de 1960 , que se completa con la Orden de 22 de julio de 1961, referente a la actuación de las autoridades municipales en esta materia, se han originado choques o entrecruzamientos de competencias que unas veces cristalizan en los mal llamados, por la Ley de conflictos jurisdiccionales de 17 de julio de 1948, conflicto de atribuciones, y que otras veces quedan abortados o amagados por no llegarse a una radicalización de las posturas respectivas de los órganos en conflicto.

De estos choques jurisdiccionales podemos citar-quizá el más reciente que conocemos-el planteado entre el Ministerio de la Gobernación y el de Obras Públicas y resuelto por la Jefatura del Estado el 17 de septiembre de 1964 (B. O. del Estado de 5 de octubre de 1964). Suscitado el conflicto entre el Gobierno Civil de Santander y la Junta de Obras del Puerto de dicha población tiene un gran interés para nosotros, ya que no hay duda de que el Gobierno Civil puede ser sustituído en casos análogos por el Ayuntamiento o, con más precisión, por 
la Alcaldía, en tanto que ésta tiene funciones gubernativas o de delegado de gobierno en la localidad reconducibles a las del Gobernador civil. No viene de ahora precisamente lo que pudiéramos llamar fricción entre el Ministerio de la Gobernación y el de Obras Públicas, a través y por órganos inscritos en la órbita funcional de ambos Departamentos, referentes a punición circulatoria.

Queremos romper una lanza en favor de la competencia municipal en esta materia que también empieza a cuartearse, por lo menos prácticamente.

$\mathrm{Y}$ sin apasionamientos creemos que fundadamente puede sostenerse que fuera de las carreteras sigue habiendo pleno apoyo legal para la competencia municipal en esta materia.

La Ley de Régimen local en la enumeración que hace, en su artículo 101, de los fines de la competencia de los Municipios, no recoge expresamente la del tráfico o circulación. Pero no debemos olvidar que las finalidades que se enumeran en dicho artículo como de la competencia municipal, sólo lo son a título enunciativo, pero no exhaustivo.

Pero el Código de la Circulación marca expresamente la atribución :al Municipio de todo lo referente a la circulación. En su artículo 12 fija taxativamente la facultad de los Ayuntamientos para establecer en la localidad disposiciones $\mathrm{u}$ ordenanzas especiales regulando la circulación dentro de sus vías, pero sin que, lógicamente, tales disposiciones puedan oponerse, alterar o desvirtuar los preceptos del Código.

Asimismo, el artículo 206, apartado B), del mismo cuerpo legal preceptúa que: «Los Ayuntamientos, de los que únicamente dependerá la policía de circulación, cuando la conservación y vigilancia del camino corresponda a su jurisdicción, se regirán por las disposiciones municipales en vigor, pero deberán hacer cumplir las disposiciones de este Código y aplicar las sanciones que en el mismo se concretan.»

$\mathrm{Y}$ desperdigadamente, en diferentes artículos del mismo Código, van recogiéndose concretamente diferentes aspectos de esta competencia, tales como velocidades máximas, supresión de señales acústicas, direcciones únicas y obligatorias, detenciones y aparcamientos, horas de carga y descarga (arts. 20,103,114, 118, 122, 123 y 124), etc.

$\mathrm{Y}$ como última expresión de esta atribución de competencia el artículo 131 dice que corresponde a las autoridades municipales sancionar las infracciones que en la circulación humana se cometan. Nos interesa ahora destacar el Decreto de 21 de julio de 1960 que, como ya hemos indicado, se refiere a competencias en materia de tráfico, circulación y 
transporte por carretera, promulgado para aplicar con carácter definitivo la Ley de 30 de julio de 1939.

El artículo $1 .^{\circ}$ de este Decreto fija que: «Corresponde al Ministerio de la Gobernación: la vigilancia de la circulación, tráfico y transporte por las vías públicas que será ejercida por las fuerzas destinadas especialmente al efecto por la Dirección General de la Guardia Civil y las que reglamentariamente se adscriban a tal servicio, sin perjuicio de la que en las ciudades se ejerza por las policías municipales; mantener la disciplina en el uso de las vías públicas mediante la Jefatura Central de Tráfico, la que, como órgano de dirección inmediata, ordenación y coordinación de las funciones asignadas a dicho Departamento le corresponderán, entre otras funciones, dictar las instrucciones a que deban ajustar su actuación las policías municipales para la observancia e interpretación de normas de circulación del Código y regulación del tráfico dentro de cascos urbanos.»

Pudiera pensarse que por el contenido del artículo $4 .^{\circ}$ del mismo Decreto, al establecer que «los Gobernadores civiles sancionarán con carácter exclusivo todas las infracciones cometidas contra la legislación de tráfico, circulación y transporte...», queda absorbida por los Gobernadores la competencia en esta materia atribuída a los Ayuntamientos, suposición que queda anulada porque ese carácter exclusivo de la competencia de los Gobernadores civiles sólo obra para delimitarla frente a la de los otros órganos de la Administración central, como son los $\mathrm{Mi}$ nisterios de Obras Públicas y de Industria a los que, de conformidad con los artículos $2 .^{\circ}$ y $5 .^{\circ}$ de la misma disposición, se les otorgan competencias referentes a la ordenación de la circulación y transporte, pero no pasando a la punición.

Resulta incontrovertible, pues, que la policía de circulación por vías urbanas es materia de la competencia municipal, y que tal competencia se puede concretar, en primer lugar, en las correspondientes normas, ordenanzas o reglamentos, bandos y órdenes, de conformidad con lo previsto en los artículos $5 .^{\circ}$ y $7 .^{\circ} \mathrm{del}$ Reglamento de Servicios de las Corporaciones locales de 17 de junio de 1955 ; y como aspecto corrector o punitivo de dicha competencia, el castigo de las infracciones sobre la materia. Sin que con ello se deba deducir que para la imposición de multas $u$ otras posibilidades punitivas sea requisito previo o condicionante el que estén establecidos tales reglamentos $\mathbf{u}$ ordenanzas, pues que las determinaciones contenidas en el Código de la Circulación pueden y deben sancionarse, aun contando con la ausencia de otras normas.

Sobre estas normas, acordadas por los Ayuntamientos o dictadas. 
por sus Presidencias, no pueden «oponerse, alterar ni desvirtuar los preceptos del Código ni inducir a confusión con ellos», de conformidad con el artículo 12 del Código de la Circulación. Por ello las disposiciones. que sobre esta materia acuerden los Ayuntamientos deben tender, como finalidad de ellas, a concretar los preceptos de tal Código, adaptándolos a las peculiaridades locales e integrando las normas que dicho cuerpo legal no perfila, sobre todo por reconducirse a la competencia municipal.

Hay que citar también la Orden del Ministerio de la Gobernación de 22 de julio de 1961, a la que ya hemos aludido, que se refiere a la. actuación de las autoridades y agentes municipales en materia de tráfico, y promulgada para desarrollo del artículo $1 .^{\circ}$, párrafo segundo $d$ ), del Decreto de 21 de julio de 1960, y en la que se declara que «para la obtención de la finalidad apetecida y en uso de las atribuciones conferidas por la Ley 47 de 30 de julio de 1959, este Ministerio ha tenido a bien disponer que los Alcaldes puedan, con potestad delegada, ordenar el tráfico dentro del núcleo urbano de la población...» (apartado IV).

La expresión usada en la Orden de 22 de julio de 1961 «con potestad delegada» está en franca antinomia con la competencia municipal en esta materia, que por tenerla es propia y no delegada. Por otra parte, hay que hacer notar que dicha. Orden, como no es la primera vez que sucede, está en abierta contradicción con disposiciones de superior categoría legislativa (Ley de Régimen local, Código de la Circulación). Es más, la referida Orden llega a estar en pugna consigo misma, toda vez que el apartado $\mathrm{V}, a$ ), de la misma preceptúa que «los Alcaldes de los Ayuntamientos a los que. afecten las presentes disposiciones dictarán las oportunas ordenanzas complementarias en bandos...». Con lo que si la circulación ha de ser normada mediante las adecuadas ordenanzas se olvida por la referida disposición que aquellas disposiciones, como es elemental, no pueden ser promulgadas por la Alcaldía, sino por el máximo órgano corporativo local: El Pleno (arts. 108, 109 y 121, h) de la Ley de Régimen local).

$\mathrm{Y}$ es visto que el Pleno no constituye un órgano delegado del Gobierno y sí solamente el Alcalde, de conformidad con los artículos 59, 117 y 118 de la Ley de Régimen local.

$\mathrm{Y}$ aunque esta materia puede ser también ordenada por bandos de la Alcaldía, a tenor de los artículos 108 de la Ley de Régimen local, y $5 .^{\circ}$ y $7 .^{\circ}$ del Reglamento de Servicios, tales medios normativos sólo deben y pueden ser utilizados para situaciones o concreciones eventuales y no para regular situaciones y problemas de carácter general y 
estable, con soluciones también de tal carácter (salvo el único caso de que tales bandos se dicten fundamentados en acuerdos $\mathfrak{u}$ ordenanzas anteriores). Ello es lógico, puesto que los bandos y las ordenanzas derivan y se fundamentan en la distinta naturaleza de los órganos que los promulgan: la Alcaldía, con potestad de mando, y el Pleno, con potestad deliberante y reglamentaria.

Si bien la potestad de mando, y en este caso su concreción, los bandos están susumidos en la deliberante, no pudiendo, por ello, contradecir ni modificar, aparte de las disposiciones del Estado, las municipales, como son las ordenanzas y reglamentos.

Así, pues, hemos de terminar diciendo que la ordenación de la circulación urbana es de competencia municipal, siendo del Ministerio de la Gobernación la figuración de carreteras y travesías, y es cada vez del máximo interés de que de esta competencia se haga uso virtual por los Ayuntamientos, y no sólo de las grandes poblaciones, ordenando la circulación dentro del respectivo núcleo urbano.

$\mathrm{Y}$ esta competencia, y ello es evidente, comprende también la corrección de las infracciones que se cometan en esta materia como claramente determina la Orden de 22 de julio de 1961, como ya hemos visto.

Rafael A.rnanz Delgado.

Secretario de 1.a categoría de Administración local. 